\title{
Individual and contextual determinants of malocclusion in 12-year-old schoolchildren in a Brazilian city
}

Lidia Moraes Ribeiro JORDÃO(a) Daniela Nobre VASCONCELOS(a) Rafael da Silveira MOREIRA ${ }^{(b)}$ Maria do Carmo Matias FREIRE(a)

(a) Universidade Federal de Goiás - UFG, Faculdade de Odontologia, Departamento de Ciências Estomatológicas, Goiânia, GO, Brazil.

(b)Ministério da Saúde - MS, Fundação Oswaldo Cruz, Instituto Aggeu Magalhães, Recife, PE, Brazil.

Declaration of Interests: The authors certify that they have no commercial or associative interest that represents a conflict of interest in connection with the manuscript.

\section{Corresponding Author:}

Lidia Moraes Ribeiro Jordão

E-mail: lidmr@hotmail.com

DOI: 10.1590/1807-3107BOR-2015.vol29.0095

Submitted: Jul 15, 2014

Accepted for publication: Apr 13, 2015

Last revision: Jun 26, 2015

\begin{abstract}
The aim of this study was to describe malocclusion prevalence and its association with individual and contextual factors among Brazilian 12-year-old schoolchildren. This cross-sectional study included data from an oral health survey carried out in Goiânia, Brazil ( $n=2,075)$, and data from the files of the local health authority. The data were collected through oral clinical examinations. The Dental Aesthetic Index (DAI) was used to assess occlusion. The presence of malocclusion (DAI > 25) was used as the dependent variable. The individual independent variables consisted of adolescents' sex and race and their mothers' level of schooling. The clinical variables were caries experience and presence of adverse periodontal condition (calculus and/or gingival bleeding). The contextual variables included type of school and the location of schools in the city's health districts. The Rao-Scott test and multilevel logistic regression were performed. The prevalence of malocclusion was $40.1 \%$. In the final model, significantly higher rates of malocclusion were found among those who attended schools located in less affluent health districts and whose mothers had fewer years of education. Rates were also higher among those presenting calculus and/or gingival bleeding. Malocclusion demonstrated a high prevalence rate and the inequalities in its distribution were determined by individual and contextual factors.
\end{abstract}

Keywords: Epidemiology; Malocclusion; Child; Social Class.

\section{Introduction}

Malocclusions rank third in priority among dental public health problems worldwide, surpassed only by dental caries and periodontal diseases. A significant increase in the prevalence and severity of malocclusions has been observed in the past few centuries. ${ }^{1}$ Malocclusions may cause decreased masticatory performance and are associated with periodontal disease and dental caries. ${ }^{2,3,4}$

Several occlusal traits depend on a combination of variations in tooth position and skeletal development, which are environmentally influenced and genetically determined. ${ }^{5}$ Since facial appearance and dental aesthetics are important for adolescents' self-esteem, untreated malocclusion has physical, psychological, and social consequences for their quality of life, and are associated with dissatisfaction with dental and gingival appearance. ${ }^{6,7}$ 
Over the last decade, greater emphasis has been placed on the importance of economic, social, and environmental factors in understanding the determinants of oral diseases. In the United Kingdom, orthodontic treatment need was more common amongst deprived children. ${ }^{8}$ In Italy, children and adolescents with a higher socioeconomic status had significantly lower orthodontic treatment needs. ${ }^{9}$ Similarly, in Brazil, severe malocclusion was higher among non-whites and public school students. ${ }^{10} \mathrm{On}$ the other hand, studies undertaken in Peru, ${ }^{11}$ Turkey, ${ }^{12}$ and India ${ }^{13}$ found no significant association between malocclusion or orthodontic treatment need and socioeconomic status.

The influence of socioeconomic factors on malocclusion is thought to occur through oral habits, psychological factors, and general patterns of disease. ${ }^{14}$ Nevertheless, Brazilian studies that used last decade's national data to examine the relationship between income inequality at a local level as well as individual factors and malocclusion prevalence found conflicting results. ${ }^{15,16}$ Therefore, the role played by individual and contextual socioeconomic determinants in dental occlusion status remains unclear. As there is inequality in dental caries and adverse periodontal conditions, ${ }^{17,18}$ socially disadvantaged adolescents were assumed to have a higher prevalence of malocclusion than their more affluent counterparts.

This cross-sectional study is one of the first to analyze the relationship between malocclusion and individual and contextual variables employing a multilevel approach. This analysis allows understanding the significance of specific contexts for individual health outcomes, and it also deals with the micro-level of individuals and the macro-level of groups simultaneously. ${ }^{19}$

A recent study ${ }^{16}$ examined the association between the prevalence of malocclusion in 12-year-olds and individual and contextual variables across Brazilian cities using multilevel modeling and found that some of their characteristics were associated with malocclusion. Our purpose is to investigate individual and contextual variables within one city, seeking to explore the existence of intra-urban inequities in the prevalence of malocclusion and its association with individual clinical variables.
Thus, the presentstudy aimed to describe malocclusion prevalence and its association with individual and contextual factors among 12-year-old schoolchildren in a Brazilian city, using a multilevel approach.

\section{Methodology}

\section{Type of study and source of data}

This cross-sectional study was carried out in Goiânia, capital city of Goiás State, in Midwestern Brazil. The analysis included primary data from an epidemiological survey carried out in 2010. Secondary data were obtained from the local health authority. The oral health survey of 12-year-old schoolchildren followed the methodology of the 2010 Brazilian National Survey of Oral Health ${ }^{20}$ and clinical examinations followed the diagnostic criteria established by the World Health Organization. ${ }^{21}$

\section{Ethical approval}

The research protocol was approved by the Ethics Committee of the Universidade Federal de Goiás - UFG (Report 226/2010), and only the children whose parents signed an informed consent form were allowed to participate in the study.

\section{Sample}

The age of 12 years was chosen following the WHO recommendations for the monitoring of children's oral health status. ${ }^{21}$ Sample size was calculated to be representative of the 12-year-old schoolchildren in the surveyed city. Because many oral conditions were investigated in the broader-scoped population survey, sample size calculation was based on the outcome of the highest required sample size (dental caries). The cluster sampling technique was used. The sample was randomly selected in two stages: the first stage unities consisted of schools while the second ones included schoolchildren.

According to State and Local Education Department data, a total of 17,911 twelve-year-olds were enrolled in 281 public and private schools in 2009. Sample size was calculated by the Epi Info ${ }^{\circ}$ software, version 3.5.1 (Centers for Disease Control and Prevention, Atlanta, USA), using an equation 
for proportions of infinite populations based on caries prevalence. It was necessary to have at least 2,171 schoolchildren as study participants. Bearing in mind the study sample design, the obtained sample size was multiplied by 1.2 (adding an extra $20 \%$ ), as a simplified and conservative correction was needed. The final sample size consisted of 2,605 schoolchildren.

To calculate the number of schools needed, the number of schools was multiplied by the number of schoolchildren in the sample and divided by the total number of 12-year-olds in the city, resulting in a sample of 41 schools. The sample was proportionally distributed into seven health districts (Central, Eastern, Northwestern, Northern, Western, Southwestern, and Southern). In each district, schools were randomly drawn using a sampling interval, which was calculated by dividing the total number of schools in each district by the total number of schools in the seven districts.

A total of 2,962 children were assessed in the 41 selected schools.

\section{Data collection}

The data were collected through oral clinical examinations by six teams, consisting of one dentist and one recorder who had been trained and calibrated according to the criteria used in the 2010 Brazilian National Survey of Oral Health. ${ }^{20}$ The inter-examiner kappa coefficient for malocclusion ranged from 0.65 to 1.00 , showing good to excellent reproducibility.

A mouth mirror and a $\mathrm{WHO}$ periodontal probe were employed, under natural light, for the intraoral examinations at the schools. The children were examined while seated in their school chairs.

The Dental Aesthetic Index (DAI), as described in the WHO manual, ${ }^{21}$ was used to evaluate occlusion. This index mathematically links the clinical and aesthetic components to achieve a single score (from 13 to 230), which combines the physical and aesthetic aspects of occlusion, ${ }^{22}$ allowing for its classification into: normal or mild (13-25), definite (26-30), severe (31-35), and very severe or handicapping malocclusion (36-230).

Other clinical variables were: caries experience, characterized by the presence or absence of visible caries in permanent teeth, and unhealthy/adverse gingival condition, assessed as presence or absence of calculus and/or bleeding on probing, measured by the Community Periodontal Index. ${ }^{21}$ Gingival bleeding and calculus were registered separately.

The following information on students' demographic and socioeconomic characteristics was collected: sex, self-reported race, and mother's level of schooling. Self-reported race followed the criteria proposed by the Brazilian Institute of Geography and Statistics (Instituto Brasileiro de Geografia e Estatística - IBGE): white, black, brown, yellow (individuals of Asian origin), or indigenous. Mother's level of schooling considered completed years of education and was obtained from the students' school records.

The secondary data included the city's health districts where the schools were located (classified according to socioeconomic indicators), and type of school (public or private).

\section{Data analysis}

The presence of malocclusion was used as the dependent variable, and assessed by the DAI score, which was dichotomized as Yes (DAI > 25) or No (DAI $\leq 25)$. The independent variables were sorted into two levels of data organization: individual (schoolchildren) and contextual (health districts and schools). At the individual level, one demographic (sex), two socioeconomic (students' race and their mothers' level of schooling), and two clinical variables (calculus and/or gingival bleeding and caries experience) were analyzed. Race was categorized into white and non-white. The mothers' level of schooling was grouped according to the Brazilian educational system as: less than eight years of schooling (incomplete lower secondary education), from eight to eleven years of schooling (complete lower or upper secondary education), and more than eleven years of schooling (admission into higher education).

The health districts where schools were located and the type of school were used as the contextual variables. The health districts were grouped according to socioeconomic characteristics, such as basic sanitation, family income, level of schooling, and housing conditions, as classified by the health authorities, as follows: Group I - Central-Campinas, with the best indicators; Group II - North, South, and East, with 
intermediate indicators; and Group III - Southwest, West, and Northwest, with the worst indicators.

The independent variables were described according to the prevalence of malocclusion using $95 \%$ confidence intervals. The Rao-Scott test checked for dependence between the variables, using the Stata $12^{\circ}$ software (Stata Corp., College Station, USA).

A multilevel analysis with random intercept ${ }^{23}$ was then conducted, considering three levels: health districts, schools, and schoolchildren, using a hierarchical model (Figure). Simple and multiple logistic regression models were adopted to estimate the odds ratio (OR) as effect measure, with 95\% confidence intervals. At each hierarchical level, the variables with P-values less than 0.25 in the bivariate analysis were tested in the multiple regression models. Variables with $p<0.05$ remained in the final model of each block. All associations were adjusted for covariates positioned at the same and at the upper levels. Multilevel analysis was performed using the MLwiN $2.02^{\circ}$ software (Centre for Multilevel Modelling, University of Bristol, Bristol, UK). The

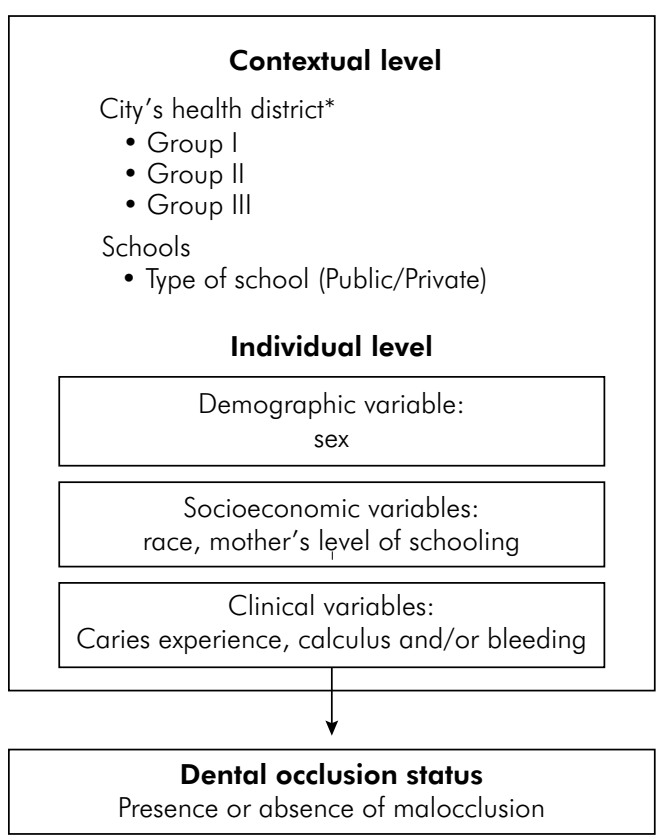

*City's health districts: Group I- with the best socioeconomic indicators, Group II- with intermediate socioeconomic indicators, and Group III- with the worst socioeconomicindicators.

Figure. Multilevel model of the association between individual and contextual variables and dental occlusion status of 12-yearold schoolchildren. Goiânia-GO, Brazil, 2010. sample weights derived from the sample design were considered for all analyses.

\section{Results}

Thirty-nine of the 41 selected schools accepted to participate in the survey, and 2,075 children out of 2,962 agreed to take part in it and were then examined (response rate $=70.0 \%$ ). The present study had a $100 \%$ power to detect significant differences in the prevalence of malocclusion between the socioeconomic groups at the $5 \%$ level. The sample was composed of males (50.9\%), non-whites (63.6\%), and children whose mothers had studied from eight to eleven years (51.2\%). Most of the students were attending public schools (71.2\%).

Normal occlusion was observed in 1,257 children (59.9\%). Definite malocclusion was detected in 417 (20.4\%), severe malocclusion in 219 (10.9\%), and very severe malocclusion in 182 individuals (8.9\%).

Table1 shows the prevalence of malocclusionaccording to the independent variables. The overall prevalence of malocclusion was $40.1 \%(n=818)$. Malocclusion was more frequent among public school children $(p=0.048)$, among those who attended schools located in Health Districts belonging to Group III ( $p=0.003$ ), and among those whose mothers studied for less than eight years $(p=0.004)$. Malocclusion was also more frequent among children with caries experience $(p=0.007)$ and in those with calculus and/or bleeding $(p=0.007)$.

Significant differences were found in the prevalence of malocclusion (Table 2) in the non-adjusted logistic regression, with greater rates among public school children $(\mathrm{OR}=1.81$, $p=0.049)$, among those from schools located in less affluent health districts $(\mathrm{OR}=2.83, \mathrm{p}=0.005$; $\mathrm{OR}=3.63, \mathrm{p}=0.002)$, and among those whose mothers had fewer years of schooling $(\mathrm{OR}=1.53$, $\mathrm{p}=0.003 ; \mathrm{OR}=2.02, \mathrm{p}=0.023)$. Rates were also higher in children with caries experience $(\mathrm{OR}=1.37$, $\mathrm{p}=0.007)$, and in those who had calculus and/or bleeding $(\mathrm{OR}=1.52, \mathrm{p}=0.007)$. No significant differences were found between males and females, nor between whites and non-whites.

After the multiple logistic regression, 'health district', mother's level of schooling, and calculus and/or bleeding remained significantly associated with malocclusion $(\mathrm{p}<0.05)$ (Table 2$)$. 
Table 1. Prevalence of malocclusion and confidence intervals $(95 \% \mathrm{Cl})$ according to independent variables. 12-year-old schoolchildren, Goiânia, Brazil, 2010.

\begin{tabular}{|c|c|c|c|c|}
\hline Contextual variables & Sample \% & Malocclusion \% & $95 \% \mathrm{Cl}^{*}$ & $\mathrm{p} \dagger$ \\
\hline \multicolumn{5}{|l|}{ Health district (group) } \\
\hline 1 & 18.4 & 20.0 & $11.3-32.9$ & \\
\hline$\|$ & 37.9 & 41.4 & $36.0-47.0$ & \\
\hline III & 43.7 & 47.5 & $36.8-58.4$ & $0.003^{* *}$ \\
\hline \multicolumn{5}{|l|}{ Type of school } \\
\hline Private & 28.8 & 30.3 & $21.1-41.5$ & \\
\hline Public & 71.2 & 44.1 & $36.1-52.4$ & $0.048^{*}$ \\
\hline Individual sociodemographic variables & Sample \% & Malocclusion \% & $95 \% \mathrm{Cl}^{*}$ & $\mathrm{p} \dagger$ \\
\hline \multicolumn{5}{|l|}{ Sex } \\
\hline Male & 50.9 & 40.0 & $33.5-46.9$ & \\
\hline Female & 49.1 & 40.2 & $32.0-49.0$ & 0.926 \\
\hline \multicolumn{5}{|l|}{ Race } \\
\hline White & 36.4 & 37.3 & $27.1-48.7$ & \\
\hline Non-White & 63.6 & 41.8 & $35.1-48.7$ & 0.360 \\
\hline \multicolumn{5}{|l|}{ Mother's level of schooling (in years) } \\
\hline More than 11 & 21.3 & 30.6 & $24.0-38.1$ & \\
\hline 8 to 11 & 51.2 & 40.3 & $32.5-48.7$ & \\
\hline Less than 8 & 27.5 & 47.1 & $38.9-55.4$ & $0.004^{* *}$ \\
\hline Individual clinical variables & Sample \% & Malocclusion \% & $95 \% \mathrm{Cl}^{*}$ & $\mathrm{p} \dagger$ \\
\hline \multicolumn{5}{|l|}{ Presence of calculus and/or Bleeding } \\
\hline No & 93.0 & 39.4 & $32.4-46.8$ & \\
\hline Yes & 7.0 & 49.7 & $39.8-59.7$ & $0.007^{* *}$ \\
\hline \multicolumn{5}{|l|}{ Caries experience } \\
\hline No & 46.0 & 36.0 & $29.4-43.2$ & \\
\hline Yes & 54.0 & 43.6 & $36.0-51.6$ & $0.007^{* *}$ \\
\hline Total & 100.0 & 40.1 & $33.1-47.6$ & \\
\hline
\end{tabular}

\section{Discussion}

The present study found that malocclusion among 12-year-old schoolchildren is associated with some individual and contextual socioeconomic factors and also with unhealthy gingival status.

Adolescents from schools located in less affluent health districts were more likely to present malocclusions than those attending schools from the most affluent health district ( $\mathrm{OR}=3.62 ; \mathrm{OR}=2.83$, for districts II and III, respectively), similar to the findings of previous studies from other parts of the world. ${ }^{8,24}$ Whenever associations between socioeconomic variables and malocclusions are reported, these could reflect differential access to orthodontic treatment. In the United States, for example, orthodontic treatment was more frequent in higher income groups, according to the third National Health and Nutrition Examination Survey, ${ }^{25}$ showing greater uptake of treatment in groups with a higher socioeconomic status.

One of the challenges of social determinants research lies in gathering adequate data that truly reflect the socioeconomic status of the population under investigation. A study conducted by Tickle et al. ${ }^{8}$ in health districts of England, for instance, used the Super Profile geodemographic classification to categorize the socioeconomic status of the participants according to their postcode. In summary, this typology 
Table 2. Results of multilevel simple and multiple logistic regression for the prevalence of malocclusion (DAI > 25). 12-year-old schoolchildren, Goiânia, Brazil, 2010.

\begin{tabular}{|c|c|c|c|c|c|c|}
\hline Contextual variables & $\mathrm{OR}^{*}$ & $95 \% \mathrm{Cl}+$ & $\mathrm{p}$ & OR & $95 \% \mathrm{Cl}+$ & $\mathrm{p}$ \\
\hline \multicolumn{7}{|l|}{ Health district (group) } \\
\hline I & 1.00 & & & 1.00 & --- & \\
\hline$\|$ & 2.83 & $1.39-5.74$ & $0.005^{* *}$ & 2.83 & $1.39-5.74$ & $0.005^{* *}$ \\
\hline III & 3.62 & $1.62-8.08$ & $0.002^{* *}$ & 3.62 & $1.62-8.08$ & $0.002^{* *}$ \\
\hline \multicolumn{7}{|l|}{ Type of school } \\
\hline Private & 1.00 & --- & & -- & -- & \\
\hline Public & 1.81 & $1.01-3.27$ & $0.049^{*}$ & --- & --- & \\
\hline Individual sociodemographic variables & OR* & $95 \% \mathrm{Cl}$ & $p$ & OR & $95 \% \mathrm{Cl}+$ & $\mathrm{p}$ \\
\hline \multicolumn{7}{|l|}{ Sex } \\
\hline Male & 1.00 & --- & & -- & -- & \\
\hline Female & 1.01 & $0.83-1.23$ & 0.926 & --- & --- & \\
\hline \multicolumn{7}{|l|}{ Race } \\
\hline White & 1.00 & --- & & -- & --- & \\
\hline Non-White & 1.21 & $0.80-1.83$ & 0.360 & -- & -- & \\
\hline \multicolumn{7}{|l|}{ Mother's level of schooling (in years) } \\
\hline More than 11 & 1.00 & --- & & 1.00 & --- & \\
\hline 8 to 11 & 1.53 & $1.06-2.20$ & $0.003^{* *}$ & 1.24 & $0.93-1.64$ & 0.129 \\
\hline Less than 8 & 2.02 & $1.28-3.18$ & $0.023^{*}$ & 1.45 & $1.06-2.00$ & $0.022^{*}$ \\
\hline Individual clinical variables & $\mathrm{OR}^{*}$ & $95 \% \mathrm{Cl}$ & $\mathrm{p}$ & OR $\ddagger$ & $95 \% \mathrm{Cl}+$ & $\mathrm{p}$ \\
\hline \multicolumn{7}{|l|}{ Presence of calculus and/or Bleeding } \\
\hline No & 1.00 & --- & $0.007^{* *}$ & 1.00 & --- & \\
\hline Yes & 1.52 & $1.13-2.05$ & & 1.40 & $1.03-1.90$ & $0.030^{*}$ \\
\hline \multicolumn{7}{|l|}{ Caries experience } \\
\hline No & 1.00 & --- & $0.007^{* *}$ & -- & -- & \\
\hline Yes & 1.37 & $1.09-1.72$ & & -- & -- & \\
\hline
\end{tabular}

classifies census districts into area types based on a scale of median income. In line with our study, Mtaya et al..$^{24}$ classified two districts of Tanzania by differences in employment and literacy rates, and proportions of the population using electricity.

At the same time, higher levels of mother's education, which was the socioeconomic variable used at the individual level in the present study, had a protective effect on their children's occlusion. In that sense, a study reported that the use of pacifiers was less frequent among children whose parents had higher education. ${ }^{14}$ It might be that low level of education and low access to health information would lead parents to allow continued use of pacifiers. However, social norms on children's soothing may vary in different contexts and cultures despite the maternal level of formal education. Deleterious oral habits and social class are indeed considered important factors in identifying children with an open bite and/or crossbite. ${ }^{26}$

Regarding the association with other oral health conditions, malocclusion rates were higher for schoolchildren that presented bleeding on probing and/or calculus, similarly to what has been reported in the literature. ${ }^{27,28}$ Tooth position anomalies, when allied to deficient oral hygiene, may negatively affect the health of gingival tissues, ${ }^{29}$ since irregular teeth tend to increase retention sites and make optimal dental cleaning harder to achieve. ${ }^{12}$ Thus, a multidisciplinary approach that includes periodontal and orthodontic 
care and also effective oral hygiene instruction is important when treating malocclusion.

The prevalence of malocclusion was higher than in the previous oral health survey carried out in the studied city in $2003 . .^{30}$ The reason for the recent increase in malocclusion frequency is thought to be the change towards more refined food, requiring less powerful masticatory action. ${ }^{1}$

Variations in reports on different associations between the prevalence of malocclusion and socioeconomic variables might be due to the wide range of malocclusion indexes and to variations in socioeconomic status measurements across the studies. There are possible limitations in using the DAI to assess malocclusion, since the DAI does not assess traits such as buccal crossbite, centerline discrepancy and deep overbite.

Another limitation of the present analysis is inherent to the type of study. Because all observations were made at one time point, they give no indication of whether exposures occurred before, during or after the onset of malocclusion, so it is not possible to infer causality. Moreover, schoolchildren who were wearing orthodontic appliances at the time of the clinical examinations were not examined for malocclusion; therefore they were excluded from

\section{References}

1. Evensen JP, Ongaard B. Are malocclusions more prevalent and severe now?. A comparative study of medieval skulls from Norway. Am J Orthod Dentofacial Orthop. 2007 Jun;131(6):710-6.

2. Magalhães IB, Pereira LJ, Marques LS, Gameiro GH. The influence of malocclusion on masticatory performance. Angle Orthod. 2010 Sep;80(5):981-7.

3. Geiger AM. Malocclusion as an etiologic factor in periodontal disease: a retrospective essay. Am J Orthod Dentofacial Orthop. 2001 Aug;120(2):112-5.

4. Baskaradoss JK, Geevarghese A, Roger C, Thaliath A. Prevalence of malocclusion and its relationship with caries among children aged 11-15 years in Southern India. Korean J Orthod. 2013 Feb;43(1):35-41.

5. Harris EF, Johnson MG. Heritability of craniometric and occlusal variables: a longitudinal sib analysis. Am J Orthod Dentofacial Orthop. 1991 Mar;99(3):258-68.

6. Bernabé E, Sheiham A, de Oliveira CM. Impacts on daily performances attributed to malocclusions by British adolescents. J Oral Rehabil. 2009 Jan;36(1):26-31. the present analysis. However, it was not possible to collect data on previous orthodontic treatment, and thus our sample may have included schoolchildren with treated and untreated malocclusion.

The individual and contextual factors studied can contribute to a more effective planning for oral health interventions in vulnerable groups, which should be implemented as early as possible, seeking to increase the proportion of the population with normal occlusion and to decrease malocclusion severity.

\section{Conclusion}

The prevalence of malocclusion in 12-year-olds was high and associated with individual and contextual variables. Inequalities in its distribution were determined by the location of schools in the city's health districts, and by mother's level of schooling. Malocclusion was also associated with adverse periodontal conditions.

\section{Acknowledgments}

We thank the Conselho Nacional de Desenvolvimento Científico e Tecnológico (CNPq), the Coordenação Nacional de Saúde Bucal, Ministério da Saúde, and the Fundação de Amparo à Pesquisa do Estado de Goiás (FAPEG) for financial support.

7. Borges CM, Peres MA, Peres KG. Association between malocclusion and dissatisfaction with dental and gingival appearance: study with Brazilian adolescents. Rev Bras Epidemiol. 2010 Dec;13(4):713-23. Portuguese.

8. Tickle M, Kay EJ, Bearn D. Socio-economic status and orthodontic treatment need. Community Dent Oral Epidemiol. 1999 Dec;27(6):413-8.

9. Deli R, Macrì LA, Radico P, Pantanali F, Grieco DL, Gualano MR, et al. Orthodontic treatment attitude versus orthodontic treatment need: differences by gender, age, socioeconomic status and geographical context. Community Dent Oral Epidemiol. 2012 Feb;40(Suppl 1):71-6.

10. Frazão P, Narvai PC. Socio-environmental factors associated with dental occlusion in adolescents. Am J Orthod Dentofacial Orthop. 2006 Jun;129(6):809-16.

11. Bernabé E, Borges-Yáñez SA, Flores-Mir C. The impact of orthodontic treatment on normative need. A case-control study in Peru. Aust Orthod J. 2007 May;23(1):50-4. 
12. Nalcaci R, Demirer S, Ozturk F, Altan BA, Sokucu O, Bostanci $\mathrm{V}$. The relationship of orthodontic treatment need with periodontal status, dental caries, and sociodemographic factors. ScientificWorldJournal. 2012;2012:1-6. doi: 10.1100/2012/498012.

13. Roopa S, Rani MS. Prevalence of malocclusion in school children of Karnataka based on the socio-economic backgrounds: a cross-sectional survey. Int J Sci Res. 2013 Sep;2(9):200-3.

14. Tomita NE, Sheiham A, Bijella VT, Franco LJ. The relationship between socioeconomic determinants and oral habits as risk factors for malocclusion in preschool children. Pesqui Odontol Bras. 2000 Apr-Jun;14(2):169-75. Portuguese.

15. Celeste RK, Nadanovsky P. How much of the income inequality effect can be explained by public policy? Evidence from oral health in Brazil. Health Policy. 2010 Oct;97(2-3):250-8.

16. Brizon VSC, Cortellazzi KL, Vazquez FL, Ambrosano GMB, Pereira AC, Gomes VE, et al. Individual and contextual factors associated with malocclusion in Brazilian children. Rev Saude Publica. 2013 Dec;47(3):118-28.

17. Hobdell MH, Oliveira ER, Bautista R, Myburgh NG, Lallo R, Narendran S, et al. Oral disease and socio-economic status (SES). Br Dent J. 2003 Jan;194(2):91-6.

18. Bonfim MLC, Mattos FF, Ferreira EF, Campos ACV, Vargas AMD. Social determinants of health and periodontal disease in Brazilian adults: a cross-sectional study. BMC Oral Health. 2013 May;13:22. doi: 10.1186/1472-6831-13-22.

19. Diez-Roux AV. Multilevel analysis in public health research. Annu Rev Public Health. 2000 May;21:171-92.

20. Roncalli AG, Silva NN, Nascimento AC, Freitas CHSM, Casotti E, Peres KG, et al. Relevant methodological issues from the SBBrasil 2010 Project for national health surveys. Cad Saude Publica. 2012;28(Suppl):s40-s57. Portuguese.
21. World Health Organization. Oral health surveys: basic methods. 4th ed. Geneva: World Health Organization; 1997. 93 p.

22. Bapu V, Gopu H. Assessment of orthodontic treatment need according to Dental Aesthetic Index. J Dent Sci Res. 2011 Sep;2(2):1-5.

23. Goldstein H. Multilevel Statistic Models. London: Arnold; 2003. $272 \mathrm{p}$.

24. Mtaya M, Brudvik P, Astrøm AN. Prevalence of malocclusion and its relationship with socio-demographic factors, dental caries, and oral hygiene in 12- to 14-year-old Tanzanian schoolchildren. Eur J Orthod Oct;2009;31(5):467-76.

25. Proffit WR, Fields HW Jr, Moray LJ. Prevalence of malocclusion and orthodontic treatment need in the United States: estimates from the NHANES III survey. Int J Adult Orthodon Orthognath Surg. 1998;13(2):97-106.

26. Hebling SR, Cortellazzi KL, Tagliaferro EP, Hebling E, Ambrosano GM, Meneghim MC, et al. Relationship between malocclusion and behavioral, demographic and socioeconomic variables: a cross-sectional study of 5-year-olds. J Clin Pediatr Dent. 2008 Fall;33(1):75-9.

27. Antunes JLF, Peres MA, Jahn GM, Levy BB. The use of dental care facilities and oral health: a multilevel approach of schoolchildren in the Brazilian context. Oral Health Prev Dent. 2006 Nov;4(4):287-94.

28. Antunes JLF, Peres MA, Frias AC, Crosato EM, Biazevic MGH. Gingival health of adolescents and the utilization of dental services, state of São Paulo, Brazil. Rev Saude Publica. 2008 Apr;42(2):191-9.

29. Gusmão ES, Queiroz RDC, Coelho RS, Cimões R, Santos RL. Association between malpositioned teeth and periodontal disease. Dental Press J Orthod. 2011 Aug;16(4):87-94.

30. Freire MCM, Reis SCGB, Gonçalves MM, Balbo PL, Leles CR. Oral health in 12-year-old students from public and private schools in the city of Goiânia, Brazil. Rev Panam Salud Publica. 2010 Aug;28(2):86-91. Portuguese. 